\title{
AS CONDIÇÕES ESPAÇO-TEMPORAIS DAS FRONTEIRAS DOS ESTADOS
}

Leonardo Luiz Silveira da Silva ${ }^{1}$

Resumo. O artigo em questão analisa as fronteiras dos Estados a partir de distintas condições espaciais e temporais. A partir desta análise, foram construídas quatro tipologias chamadas de condições espaço-temporais da fronteira. $\mathrm{Na}$ abordagem do artigo, privilegia-se uma análise mais detida acerca da situação da fronteira brasileira, como estratégia de comunicação ao leitor. Ressalta-se, por meio deste texto, que ascategorias propostas não se apresentam como etapas necessárias de um processo evolutivo irremediável. Além disso, a existência de categorias não implica na crença de que uma fronteira se enquadre plenamente em seus termos, abrindo a possibilidade para a existência de características de distintas tipologias em um mesmo espaço analisado.

Palavras-Chave: Fronteiras; Estado; Categorias.

\section{THE SPACE-TIME CONDITIONS OF STATE BOUNDARIES}

Abstract. The article analyzes the state boundaries from different spatial and temporal conditions. From this analysis, four typologies were constructed, called space-time boundary conditions. In the approach of the article, a more focused analysis about the situation of the Brazilian border has been made, as a strategy of communication to the reader. It is emphasized, through this text, that the categories proposed are not presented as necessary stages of an irremediable evolutionary process. Moreover, the existence of categories does not imply the belief that a frontier frame in its terms, opening the possibility for the existence of characteristics of different typologies in the same space analyzed.

Keywords: Boundaries; State; Categories.

\section{LAS CONDICIONES ESPACIO-TEMPORAIS DE LAS FRONTERAS DE LOS ESTADOS}

Resumen.El artículo analiza las fronteras de los Estados a partir de distintas condiciones espaciales y temporales. A partir de este análisis, fueron construidas cuatro tipologías llamadas de condiciones espacio-temporales de la frontera. En el abordaje del artículo, se privilegia un análisis acerca de la situación de la frontera brasileña, como estrategia de comunicación al lector. Se resaltaque las categorías propuestas no se presentan como etapas necesarias de un proceso evolutivo irremediable. Además, la existencia de categorías no implica la creencia de que una frontera se encuadre plenamente en sus términos, abriendo la posibilidad para la existencia de características de distintas tipologías en un mismo espacio analizado.

Palabras clave: Fronteras; Estado; Categorías.

\footnotetext{
${ }^{1}$ Mestre em Relações Internacionais (PUC-MG) e Doutor em Geografia (PUC-MG). Professor efetivo do IFNMG-campus Salinas. Email: leoluizbh@hotmail.com
} 


\section{Introdução}

As fronteiras dos Estados passaram por um verdadeiro processo de ressignificação desde a fundação da ordem vestfaliana. Outrora entidades mal definidas que abrigavam poderes estatais débeis e incapazes de exercer esplêndida territorialização no espaço, as fronteiras passaram por um inegável processo de fortalecimento. Este processo se explica, por sua vez, pelo entendimento por parte do Estado do seu valor estratégico, materializado no aperfeiçoamento dos instrumentos de territorialização e na concentração de políticas voltadas para o espaço fronteiriço. Contudo, a ordem pós Guerra Fria marcou uma nova significação da fronteira, que passou a ser porosa mediante a natureza dos fluxos transnacionais que marcam a contemporaneidade. Apresenta-se ainda como uma condição contemporânea as fronteiras em colapso, fato diretamente ligado à desterritorialização do espaço.

Há de se considerar o caráter relativamente polissêmico da fronteira, sendo entendida neste artigo como as fronteiras dos Estados, que são, no sentido prático, áreas definidas pelos próprios Estados de acordo com os seus interesses estratégicos (constituindo-se, na prática, como faixa de fronteira). Esta discussão conceitual será apresentada no próximo tópico.

O artigo em questão objetiva mostrar a mudança dos sentidos da fronteira a partir das quatro condições espaço-temporais: a fraqueza, a força, a porosidade e o colapso, apresentando, a partir de observações sobre a fronteira brasileira e outras, de que forma estas condições impactaram na realidade geopolítica do Estado.

Há uma tentativa de se evitar o uso da palavra "estágios" se referindo as distintas condições da fronteira ao longo do tempo. Esta tentativa se explica pela associação inequívoca da palavra estágio frente a uma lógica positivista-determinista que simplifica a diversidade e complexidade da fronteira entendida enquanto categoria geográfica. A palavra estágio ainda denota uma evolução linear, o que não se aplica ao caso das chamadas condições espaço-temporais da fronteira. O uso da expressão "condição espaço-temporal" não é um eufemismo determinista; trata-se de um convite à compreensão do dinamismo da fronteira, de sua heterogeneidade enquanto periferia de uma entidade territorial e da possibilidade das fronteiras se apresentarem plurais tanto no tempo quanto espaço. Afinal, quem poderia, na integridade de suas faculdades cognitivas, imaginar a fronteira de colossos territoriais como a Rússia ou o Brasil como espaços homogêneos?

Há de se considerar que as condições espaço-temporais da fronteira não se modificam em todos os Estados ao mesmo tempo. Fronteiras ainda permanecem fortes enquanto outras 
são notavelmente porosas ou ainda colapsadas. Contudo, é plausível considerar que eventos marcantes em escala global possam impactar, a seu modo, cada uma das fronteiras. Como foi alertado, também certo que as condições espaço-temporais da fronteira não precisam seguir uma lógica linear. Tampouco precisam ser identificadas em cada estudo de caso, enquadrando-se, claramente, como tipologias dotadas de significados imprecisos cujo a maior relevância de sua reflexão está justamente na relativização do conceito de fronteira enquanto categoria geográfica. Afinal, é plausível considerar que determinadas fronteiras possam reunir, ao mesmo tempo e no mesmo espaço, diferentes elementos das tipologias fronteiriças espaço-temporais aqui propostas.

$\mathrm{O}$ artigo em questãose desenvolve em outras sete partes além desta introdução. A primeira delas traz uma abordagem conceitual sobre limites e fronteiras. A segunda versará sobre a fraqueza das fronteiras. A terceira abordará a condição espaço-temporal da força das fronteiras, enquanto que a quarta parte, por sua vez, contemplará a porosidade. A quinta versará sobre as fronteiras em colapso enquanto que a sexta parte trará um quadro síntese sobre as condições espaço temporais das fronteiras. Finalmente, por último, serão apresentadas as considerações finais.

\section{Os limites e as fronteiras}

Quando imaginado na realidade territorial dos Estados modernos, consideramos que limite é a linha natural ou artificial que contorna o extremo do território físico do Estado. Para Lia Osório Machado (2000), o limite jurídico do território é "uma abstração, gerada e sustentada pela ação institucional no sentido do controle efetivo do Estado territorial, portanto, um instrumento de separação entre unidades políticas e soberanas" (MACHADO, 2000, p.9-10). Já a fronteira, é a faixa contígua à linha do limite. Usualmente os Estados estabelecem a extensão desta faixa, fato que restringe o universo semântico do termo, findando as brechas para as interpretações subjetivas.

Existe uma confusão relativamente comum acerca da diferença entre os conceitos de fronteira e faixa de fronteira. A primeira possui definição informal, enquanto a segunda possui uma definição jurídico/administrativa. A faixa de fronteira pode ser entendida como uma realidade concreta. Não há subjetividade neste conceito, pois se refere a uma área convencionada estabelecida por países ou outras formas de organização política segundo as normas do direito internacional, leis e constituições dos envolvidos (ABINZANO, 2005). Entre os países, existem diferenças na definição destas faixas fronteiriças, que acabam por ser 
estabelecidas por lei e submetidas a algum tipo de regulamentação específica, conforme os interesses do Estado que nela exerce a soberania. Para o Brasil a sua dimensão é assim definida pela Constituição Federal:

A faixa de até $150 \mathrm{~km}$ de largura, ao longo das fronteiras terrestres, designada como faixa de fronteira, é considerada fundamental para a defesa do território nacional e sua ocupação e utilização serão regulamentadas por lei (BRASIL, Cap.II, Art.20, alínea XI, parágrafo II, 1988).

A Bolívia, por exemplo, tem a extensão da faixa de fronteira três vezes menor do que brasileira. Nesta faixa, a Bolívia tem feito um esforço para evitar a presença de estrangeiros como proprietários de terras, movimento que se acentuou no governo de Evo Morales. Assim diz o trecho da Constituição Boliviana sobre o assunto:

Constitui-se zona de segurança de fronteira os cinquenta quilômetros a partir da linha da fronteira. Nenhuma pessoa estrangeira, individualmente ou em sociedade, poderá adquirir propriedade neste espaço, direta ou indiretamente, nem possuir nenhum título de propriedade de água, solo ou subsolo. A propriedade ou a posse afetada em caso de descumprimento desta proibição passarão ao benefício do Estado sem nenhuma indenização. A lei poderá prever exceções a esta proibição (BOLÍVIA, Art.261, linha I, 2009).

A extensão que envolve a soma territorial de duas faixas de fronteira adjacentes é chamada de Zona de Fronteira (MACHADO, et. al.,2005). Deste modo, a Zona de Fronteira boliviano-brasileira possui $200 \mathrm{~km}$ de extensão (sendo $150 \mathrm{~km}$ dentro do território brasileiro e $50 \mathrm{~km}$ no território boliviano).

Por outro lado, a definição de fronteira é mais frouxa, podendo ser aplicada às diversas realidades: falam-se de fronteiras entre as jurisdições regionais, províncias, estados e municípios; nestes casos de divisões internas, normalmente o conceito de fronteira se confunde com o de limite (MATTOS,1990). Sendo uma região periférica, a fronteira é a faixa de contato com outras soberanias, com o mar ou com o espaço aéreo cujos limites jurisdicionais e direito de utilização são regulados por leis internacionais. Por isso se trata de uma região sensível, onde os direitos soberanos dos Estados se contatam fisicamente (MATTOS, 1990). Enquanto a fronteira é considerada uma fonte de perigo ou ameaça porque pode desenvolver interesses distintos aos do governo central, o limite jurídico do Estado é criado e mantido pelo governo, não possuindo vida própria e se tratando de um polígono. (MACHADO, 1998).

As fronteiras terrestres são as de questionamento mais antigo, por isso mesmo encontra-se bastante consolidado o direito internacional que regula o seu traçado e a sua funcionalidade. A aceitação de uma linha de limites pelos países confinantes seja natural ou 
artificial, não deve dispensar a necessidade de sua demarcação física. Quando se trata de fronteiras naturais tais como rios, lagos, montanhas, cordilheiras ou desertos, há várias regras de demarcação já consagradas por critérios internacionais (MATTOS, 1990). Parte expressiva do limite entre o Brasil e a Bolívia é definido pelo contorno fluvial, quando é usado como marco regulador da fronteira o talvegue. Isto não impede que ilhas fluviais sejam alvo de disputa territorial, como se vê no rio Mamoré, justamente no espaço entre as cidades gêmeas de Guajará-Mirim (Rondônia-Brasil) e Guayaramerín (Beni-Bolívia).

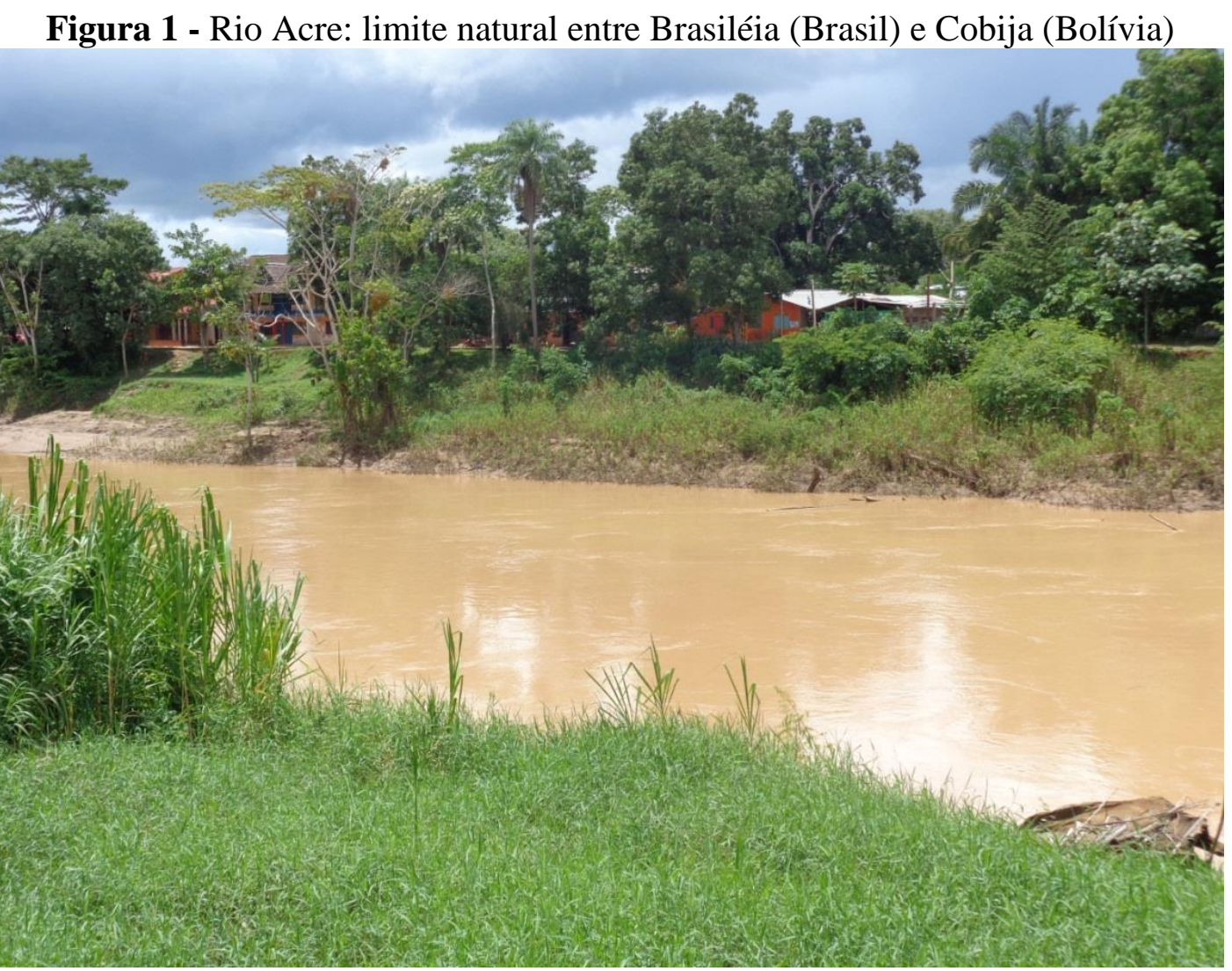

Fonte: Foto do autor

Cássio Eduardo Viana Hissa no livro "A mobilidade das fronteiras", traz uma reflexão epistemológica acerca dos conceitos de fronteiras e limites. Segundo Hissa (2002), fronteiras e limites fornecem imagens conceituais equivalentes. Contudo, o autor desenvolve as diferenciações entre os conceitos ao considerar que

(...) o limite está voltado para dentro, enquanto a fronteira, imaginada do mesmo lugar, está voltada para fora, como se pretendesse a expansão daquilo que lhe deu origem (...).

(...) O limite estimula a ideia sobre a distância e a separação, enquanto a fronteira movimenta a reflexão sobre contato e a integração (...)

(...) O limite almeja a precisão e se insinua como muro, mas, contraditoriamente, por estar contido na fronteira e através dela, apresenta-se também como uma transição (HISSA, 2002, p.35). 
Uma reflexão sobre limites e fronteiras é, também, uma reflexão sobre o poder (HISSA, 2002). As oscilações espaciais dos limites e das fronteiras após a expansão da ideia do Estado moderno pós-vestfaliano foram notáveis e revelam as mudanças nas relações de poder que se manifestam no espaço em diferentes escalas e exercidas por diversos atores. A fronteira é um lugar de comunicação e troca. Os povos podem se expandir para além do limite jurídico do Estado, desafiar a lei territorial de cada Estado limítrofe e às vezes criar uma situação de facto, potencialmente conflituosa, obrigando a revisão dos acordos diplomáticos(MACHADO, 2000). É justamente o papel estratégico da fronteira que motiva a mesma ser tratada em parte da literatura como sinônimo de limite, como esclarece Lia Osório Machado:

Não é surpresa, portanto, que a fronteira, historicamente, tem sido objeto permanente de preocupação dos Estados, no sentido de controle e vínculo. Tampouco é surpreendente que um dos objetivos do sistema histórico de Estados Nacionais, em vigência por quase dois séculos, foi o de estimular a coincidência entre limite e fronteira, disso resultando uma convergência conceitual, a ponto de serem consideradas na literatura como sinônimos (MACHADO, 2000, p.10).

A mesma autora argumenta que a convergência conceitual entre limites e fronteiras deve ser revista frente aos novos agenciamentos do poder político e econômico e do espaço físico mundial. As principais manifestações destas mudanças têm sido, de um lado, os agrupamentos funcionais de Estados (expressos por intermédio dos blocos econômicos internacionais), a proliferação de organizações internacionais e transnacionais e as migrações internacionais; de outro lado, "as formas de organização em rede, possibilitadas pela revolução tecnológica dos meios de comunicação e informacionais, rápidos em redefinir espaços de transação não coincidentes com o espaço territorial dos Estados nacionais" (MACHADO, 2000, p.10). É por causa desta segunda manifestação que a mensuração dos fluxos transnacionais é fator precípuo para atestar a soberania em risco, sobretudo em áreas limítrofes. Considerando que rede, território e poder são conceitos entremeados, é plausível admitir que as nações mais poderosas "são capazes, às vezes, de instrumentalizar os fluxos transnacionais e de melhorar o seu ascendente sobre os mais fracos" (BADIE, 1995, p.206). O desarranjo das redes transnacionais em relação aos limites estatais se explica em boa parte pelo uso que os próprios Estados fazem de sua soberania, argumento endossado por Bertrand Badie (1999).

A transnacionalidade do arranjo das redes contribui para o entendimento da ascensão de atores que diluem a soberania Estatal. Assim, a intensificação da difusão, da diversidade e 
da densidade das redes contribui para reforçarmos a crença de que uma abordagem meramente pautada na soberania e na exclusão de atores não-estatais no jogo político internacional é insuficiente para o fazer geopolítico contemporâneo. Esta temática é central para entendermos as mudanças que as fronteiras tem experimentado na contemporaneidade e que serão contempladas paulatinamente nos tópicos a seguir.

\section{A fraqueza das fronteiras}

É difícil conceber um Estado recém institucionalizado que já nasça com as fronteiras fortes. Mesmo em Estados há muito tempo territorializados, é importante considerarmos a natureza desequilibrada da territorialização. Não é raro observarmos Estados em que o seu centro de controle e comando se situa distante das áreas próximas aos limites internacionais. As redes, importantes instrumentos de territorialização, convergem preferencialmente para os centros de maior relevância, fazendo destes nós importantes da malha que recobre o território e concomitantemente o territorializa. Deste modo, a malha que repousa sobre o território assume densidades diferentes, que aludem diretamente à capacidade do ator que rege o espaço em questão de exercer o poder sobre ele. É amplamente conhecida na literatura acadêmica a associação íntima entre as categorias geográficas rede e território.

As redes, por meio de sua densidade, territorializam o espaço. Para Raffestin, o Estado "só recorta o espaço em malhas mais ou menos cerradas por uma única razão: deve encontrar a malha mais adequada para, levando em consideração os seus meios, ver o melhor possível” (RAFFESTIN, 2011, p.35). Claude Raffestin utiliza a palavra "ver" como sinônimo de "exercer o poder", pois é sabido que o autor em questão faz uma analogia com a ideia do panóptico foulcautiano, permitindo a associação de cunho geográfico entre os verbos "ver" e mesmo "conhecer" com "dominar" ou "exercer o poder". O realocamento das capitais observado durante o século XX em alguns países teve como uma de suas funções a correção de desequilíbrios territoriais, como foi o caso do Brasil (Rio de Janeiro-Brasília), Nigéria (Lagos-Abuja) e Costa do Marfim (Abjdã-Yamossoucro).

A faixa de fronteira, muitas vezes, encontra-se demograficamente esvaziada, com redes pouco densas, sendo, portanto, um espaço com menor territorialização. Estas características se devem, em grande parte, ao caráter periférico frente aos centros de controle e comando territoriais. Em Estados recém criados, as ligações entre centro e periferia, via de regra, encontravam-se ainda mais frágeis, sendo uma ação características destes Estados a 
fundação de cidades junto aos limites territoriais, que cumpririam, pelo menos no que tange às suas características fundadoras, o posto de cidades-vigilantes. A fundação destas cidades, bem como a construção de postos aduaneiros junto aos limites são marcos fundamentais para a mudança da condição espaço-temporal da fronteira, dando início ao abandono do status das fronteiras, fortalecendo-as.

No passado, as limitações técnicas foramum fator de risco para a determinação dos limites dos Estados, ainda que muitos tenham utilizado acidentes geográficos de destaque como rios ou interflúvios para a demarcação dos seus contornos territoriais.As melhorias técnicas, dentre outros fatores, colaboraram para o adensamento das redes de ordem econômica, demográfica, de transportes, dentre outras, proporcionando a territorialização do espaço e dando força às regiões fronteiriças, legitimando-as e tornando-as parte do território de facto e de jure.

No período pré-colonial brasileiro não era fácil estabelecer com exatidão o Meridiano de Tordesilhas; não tinha ficado estabelecido de que ponto do arquipélago de Cabo Verde se começava a medir as 370 léguas (ANDRADE, 1993) que serviam como definição da linha imaginária. Ainda mais problemático era o fato da posição aproximada de Tordesilhas cortar dois pontos de grande importância geopolítica: a foz do Amazonas e a foz do rio da Prata.

No caso da formação territorial brasileira, é importante considerar queas pendências fronteiriças entre portugueses e espanhóis na América do Sul se estenderam por mais de um século após o fim da União Ibérica. Os portugueses queriam manter as áreas que ocuparam durante o período de união e os espanhóis queriam um recuo do povoamento português até a linha de Tordesilhas. O diplomata Alexandre de Gusmão participou ativamente das negociações para um novo arranjo territorial da América do Sul utilizando como defesa da posição portuguesa o princípio jurídico latino uti possidetis, argumentando que o direito do território deveria caber ao povo que o povoara (ANDRADE, 1993). O produto destas negociações foi o Tratado de Madri, concluído em 1750. Com ele, as fronteiras entre as terras portuguesas e espanholas aproximaram-se das fronteiras atuais do Brasil com os países hispano-americanos. Porém, na porção meridional, na bacia do Prata, a linha fronteiriça sofreria modificações posteriormente. A experiência da formação territorial brasileira e definição dos limites corresponderam a uma das experiências históricas mais significativas em termos comparativos, em função da existência de $16.000 \mathrm{~km}$ de fronteira compartilhados com dez Estados limítrofes (CERVO e BUENO, 2012). Com a sua independência em 1822, já 
tendo sido estabelecidos o Tratado de Madri (1750) e o de Santo Ildefonso (1777), o Brasil herdou uma situação de facto confortável, de jure delicada.

No período pós-independência, o princípio uti possidetis norteou as negociações territoriais brasileiras. Os governos dos demais países sul-americanos, sucessivamente, exprimiam sua adesão à doutrina do uti possidetis, convertendo-a numa doutrina latinoamericana de direito internacional público (CERVO e BUENO, 2012). Este é o momento em que a fronteira brasileira passou, de facto e de jure, a se fortalecer.

\section{A força das fronteiras}

A fundação das cidades vigilantes, o reconhecimento dos limites por parte dos Estados vizinhos e o adensamento das redes são forças fundamentais para o fortalecimento da faixa de fronteira. Um ato complementar de fortalecimento é a definição institucional da extensão da faixa de fronteira e a aplicação de políticas territoriais que visam o desenvolvimento econômico orientado para o espaço intranacional. Afinal, políticas que favoreçam a atuação de redes transnacionais são características de uma outra condição espaço-temporal da fronteira: a porosidade.

Por se tratarem de áreas estratégicas ao Estado, é uma condição não raro observada o estabelecimento de políticas territoriais especiais. O Brasil vem desenvolvendo zonas especiais nas áreas de fronteiras no intuito de garantir a sua soberania e, em tese, estimular a cooperação. Tanto o SIVAM (Sistema de Vigilância da Amazônia) quanto o projeto Calha Norte aludem à preocupação do governo federal com as fronteiras subpovoadas da Amazônia brasileira. De forma notável se destaca, como outra iniciativa, o PDFF (Programa de Desenvolvimento da Faixa de Fronteira). A sua existência é justificada a partir do segundo argumento:

A preocupação com a segurança nacional, de onde emana a criação de um território especial ao longo do limite internacional continental do país, embora legítima, não tem sido acompanhada de uma política pública sistemática que atenda às especificidades regionais, nem do ponto de vista econômico nem da cidadania fronteiriça. Motivos para isso não faltaram até o passado recente, como a baixa densidade demográfica, a vocação "atlântica" do país, as grandes distâncias e as dificuldades de comunicação com os principais centros decisórios, entre outros (BRASIL, 2005, p.9) 
O PDFF é grandioso em diversos aspectos. Ao todo são 588 municípios da Faixa de Fronteira brasileira que são contemplados. Tais municípios apresentam situação geográfica distinta em relação à linha de fronteira ${ }^{2}$, como consta na tabela:

Quadro 1 - Características dos municípios contemplados pela PDFF

\begin{tabular}{|c|c|}
\hline Tipo de Município contemplado pela PDFF & Característica \\
\hline \multirow{3}{*}{ Lindeiro } & $\begin{array}{l}\text { O território do município faz limite com o país } \\
\text { vizinho e sua sede se localiza no limite internacional, } \\
\text { podendo ou não apresentar uma conurbação ou } \\
\text { semiconurbação com uma localidade do país vizinho } \\
\text { (cidades-gêmeas). }\end{array}$ \\
\hline & $\begin{array}{l}\text { O território do município faz divisa com o país } \\
\text { vizinho, mas cuja sede não se situa no limite } \\
\text { internacional. }\end{array}$ \\
\hline & $\begin{array}{l}\text { O território do município faz divisa com o país } \\
\text { vizinho, mas cuja sede está fora da Faixa de Fronteira. }\end{array}$ \\
\hline & $\begin{array}{l}\text { O município não faz divisa com o país vizinho e a sua } \\
\text { desse situa-se dentro da faixa de fronteira. }\end{array}$ \\
\hline Não-Lindeiro & $\begin{array}{l}\text { O município não faz divisa com o país vizinho, possui } \\
\text { apenas parte do seu território inserido na Faixa de } \\
\text { Fronteira e sua sede municipal situa-se fora da faixa } \\
\text { em questão. }\end{array}$ \\
\hline
\end{tabular}

Fonte: BRASIL, 2005, organizado pelo autor.

A grande extensão territorial da Faixa de Fronteira brasileira concomitantemente aos diferentes sensos de territorialidade, distribuição e densidade dos meios de territorialização motivaram a regionalização da faixa de fronteira brasileira, que foi dividida em três grandes regiões e diversas sub-regiões, conforme o quadro a seguir:

Quadro 2 - Regiões e suas respectivas Sub-Regiões estabelecidas pelo PDFF

\begin{tabular}{|c|l|}
\hline \multicolumn{1}{|c|}{ Região } & \multicolumn{1}{c|}{ Sub-região } \\
\hline \multirow{2}{*}{} & Oiapoque-Tumucumaque \\
\cline { 2 - 2 } & Campos do Rio Branco \\
\cline { 2 - 2 } & Parima-Alto Rio Negro \\
\cline { 2 - 2 } Arco Norte & Alto Solimões \\
\hline
\end{tabular}

\footnotetext{
${ }^{2}$ Linha que estabelece o limite da faixa de fronteira definido pela lei brasileira (150 km de extensão a partir do limite do território nacional).
} 


\begin{tabular}{|c|c|}
\hline & Alto Juruá \\
\hline & Vale do Acre-Alto Purus \\
\hline \multirow{8}{*}{ Arco Central } & Madeira-Mamoré \\
\hline & Fronteira do Guaporé \\
\hline & Chapada dos Parecis \\
\hline & Alto Paraguai \\
\hline & Pantanal \\
\hline & Bodoquena \\
\hline & Dourados \\
\hline & Cone Sul Matogrossense \\
\hline \multirow{3}{*}{ Arco Sul } & Portal do Paraná \\
\hline & Vales Coloniais Sulinos \\
\hline & Fronteira da metade sul do rio Grande do Sul \\
\hline
\end{tabular}

Fonte: BRASIL, 2005, organizado pelo autor.

O PDFF tem como objetivo principal promover o desenvolvimento da Faixa de Fronteira, por meio de sua estruturação física, social e produtiva, com ênfase na ativação das potencialidades locais e na articulação com outros países da América do Sul (BRASIL, 2009, p.12). Há uma crença, dos gestores do programa, de que os atores locais, uma vez fortalecidos, vão protagonizar “o processo de desenvolvimento endógeno e sustentável, resultando no fortalecimento de novos eixos dinâmicos da economia" (BRASIL, 2009, p.14).

Compõem as diretrizes do PDFF:

A) Fortalecimento Institucional: refere-se a diversas ações que visam a participação público-privada no processo decisório de gestão das demandas das áreas de fronteira, bem como o estímulo para a participação de atores transnacionais;

B) Desenvolvimento econômico integrado: refere-se a incentivos diversos no investimento em infraestrutura facilitadora do desenvolvimento econômico bem como um esforço tarifário para a redução de custos da telefonia em área de fronteira; 
C) Condições de Cidadania: diz respeito ao desenvolvimento de programas de defesa de direitos humanos, do incentivo à preservação da cultura e ao exercício pleno da cidadania;

D) Marco Regulatório/Legal: diz respeito ao esforço para o desenvolvimento de um estatuto geral para a zona de fronteira e, caso a caso, de acordo com o que se estabelece com cada país vizinho, estatutos mais detalhados para relações bilaterais (BRASIL, 2009).

Concomitante à ação brasileira do PDFF, estão as Áreas de Livre Comércio (ALCs). Tais áreas foram criadas para promover o desenvolvimento das cidades de fronteiras internacionais localizadas na Amazônia Ocidental e em Macapá e Santana, com o intuito de integrá-las ao país (SUFRAMA, 2013). No sentido prático, oferecem benefícios físcais semelhantes aos da Zona Franca de Manaus no aspecto comercial. Os incentivos concentramse na isenção do Imposto sobre Produtos Industrializados (IPI) e do imposto sobre circulação de Mercadorias e Prestação de Serviços (ICMs).

Quadro3 - Cidades contempladas pelo regime das ALCs

\begin{tabular}{|c|c|c|}
\hline Cidade & Unidade da Federação & Cidade-Gêmea \\
\hline Boa Vista & Roraima & Não \\
\hline Bonfim & Roraima & Sim \\
\hline Guajará-Mirim & Rondônia & Sim \\
\hline Brasiléia & Acre & Sim \\
\hline Epitaciolândia & Acre & Sim \\
\hline Cruzeiro do Sul & Acre & Não \\
\hline Tabatinga & Amazonas & Não \\
\hline Macapá & Amapá & Não \\
\hline Santana & Amapá & \\
\hline
\end{tabular}

Fonte: SUFRAMA, 2013.

Como informa a tabela, nem todas as cidades de fronteira contempladas pelo regime das ALCs se enquadram na categoria de cidades gêmeas, que são conurbações transfronteiriças. Ainda assim, devido à relevância estratégica da faixa de fronteira, recebem o incentivo fiscal, possibilitando que o preço de inúmeros produtos industrializados seja mais 
competitivo. Sem o incentivo, a faixa fronteiriça brasileira, sobretudo no grande arco que envolve a Região Norte, pode melhor se associar às redes transfronteiriças do que ao conjunto do espaço nacional, fragilizando assim o exercício do poder do Estado sobre aquela porção territorial estratégica. A competitividade da produção nacional nas áreas distantes dos parques industriais brasileiros é realçada por meio das políticas de incentivos fiscais. Senhoras (2013) destaca que um dos principais objetivos da criação das ALCs é a promoção do desenvolvimento das cidades amazônicas localizadas na faixa de fronteira. Isso se dá em razão dos vazamentos de renda de brasileiros que facilmente têm trânsito de compra nas cidades fronteiriças dos países vizinhos (Guiana, Venezuela, Colômbia, Peru e Bolívia).

As cidades de fronteira, assim como qualquer núcleo urbano, são, em alguma medida, eixos articuladores das relações que se dispõem sobre o território no qual estão inseridas. Ao examinar o papel das cidades na contemporaneidade, Ash Amin (2002) escreve que as cidades não podem ser vistas como unidades territoriais restritas, mas por intermédio das múltiplas relações que por elas são engendradas. Pensando nesse sentido, os incentivos fiscais que atuam nas cidades localizadas no espaço fronteiriço buscam realçar o papel de articulação dos fluxos das redes que se dispõem no território, fazendo delas um posto avançado de territorialização do espaço nacional. As cidades gêmeas da Região Norte são alvos preferenciais das políticas de incentivo do governo, dado a forte atuação das redes transfronteiriças sobre o seu espaço.

A regulamentação das ALCs prevê, além da isenção do IPI e do ICMS de produtos que são internados nas municipalidades (nas áreas urbanas), a ausência de impostos de importação. Contudo, algumas cidades brasileiras veem o regime de ALCs funcionar parcialmente: desfrutam da isenção do IPI e ICMS sem a isenção para importar. Os resultados desta condição são claros: privilegia-se o fortalecimento de redes que articulam a faixa de fronteira ao espaço intranacional.

Tabela 1 - Operação das Áreas de Livre Comércio

\begin{tabular}{cccccc}
\hline UF & ALC & $\begin{array}{c}\text { ALC } \\
\text { Regulamentada }\end{array}$ & $\begin{array}{c}\text { Empresas } \\
\text { Cadastradas no } \\
\text { Suframa }\end{array}$ & $\begin{array}{c}\text { Empresas aptas } \\
\text { para receberem } \\
\text { o benefício } \\
\text { fiscal }\end{array}$ & $\begin{array}{c}\text { Volume de Importações } \\
\text { em US\$ }\end{array}$ \\
AM & Tabatinga & Sim & 181 & 72 & $509.961,38$ \\
RO & Guajará-Mirim & Sim & 1081 & 372 & $2.906 .876,51$ \\
RR & Boa Vista & Sim & 3450 & 1680 & $2.978 .566,42$ \\
RR & Bonfim & Não & 30 & 08 & 0 \\
\hline
\end{tabular}




\begin{tabular}{cccccc}
\hline AP & $\begin{array}{c}\text { Macapá- } \\
\text { Santana }\end{array}$ & Sim & Não Informado & Não Informado & $28.198 .907,99$ \\
AC & $\begin{array}{c}\text { Brasiléia- } \\
\text { Epitaciolândia }\end{array}$ & Não & 491 & 159 & 0 \\
AC & Cruzeiro do Sul & Não & 503 & 292 & 0 \\
\hline
\end{tabular}

Fonte: Senhoras, 2013.

Assim, o Brasil, por meio de suas políticas territoriais especiais aplicadas à fronteira, ajuda a aumentar a diversidade das características desta, criando:

- zonas em que a porosidade surge como uma condição espaço-temporal da fronteira, nas quais o arranjo de redes transnacionais é estimulado;

- zonas em que a força das fronteiras se faz mais presente, por intermédio do incentivo ao arranjo de redes voltadas para o espaço intranacional;

- zonas de indiferença, que as políticas das ALCs não são válidas, como na Faixa de Fronteira do Centro-Sul brasileiro.

As razões para esta diferença exigem estudos direcionados para estas questões, sendo precoce assumir posições acerca destas assimetrias na fronteira brasileira.

\section{A porosidade das fronteiras}

A porosidade das fronteiras é uma condição espaço-temporal que exige o beneplácito do Estado. A porosidade denota uma condição entre a permeabilidade e a impermeabilidade absoluta. Ou seja, ainda que denote uma situação de fluidez transnacional da faixa de fronteira, a porosidade transmite uma ideia de fluxos permitidos. Os fluxos ilegais, que independem do Estado, são difíceis de serem mensurados. Tornam-se uma realidade nociva a partir da condição espaço-temporal da força das fronteiras. Afinal, na fraqueza o espaço fronteiriço é mal institucionalizado, não sendo coerente esperar que os fluxos atendam aos interesses de um poder centralizado que atua incipiente em sua zona periférica. Na condição de porosidade os fluxos ilegais também estão presentes, sendo um problema maior quanto menor for a força do Estado. Assim, a condição de porosidade da fronteira (no sentido em que a categorização é trabalhada neste texto) depende da condição da força da fronteira. 
As notáveis melhorias dos transportes e comunicações implicaram em um novo quadro no que tange aos arranjos dos fluxos transnacionais. A condição da porosidade das fronteiras está diretamente ligada à intensificação do processo de globalização. Bertrand Badieargumenta que, na contemporaneidade, o Estado aprendeu a ceder a sua soberania em prol de benefícios econômicos. Isto não significa necessariamente enfraquecer o papel do Estado, mas fazer concessões esporádicas e/ou pontuais que possuem o intento de gerar benefícios para o mesmo. Assim diz o autor:

O fosso que se cava entre o Estado e soberania pode surpreender, mas tornase um dos parâmetros do jogo internacional contemporâneo. Esta crise pode observar-se a partir de inúmeros pontos de vista. Em primeiro lugar, são muitos os actores [sic passim]extra-estatais que pretendem manipular ou utilizar a detenção do poder último: empreendedores identitários, religiosos ou comunitários, empreendedores transnacionais, actores políticos que procuram construir a sua legitimidade sobre a salvaguarda de uma soberania atacada. Depois porque o Estado, em face destes novos concorrentes e perante novos dados da mundialização, muda progressivamente de método: em vez de validar sua acção [sic] pelo recurso ao princípio da soberania territorial, ele inscreve-se nas redes transnacionais, negocia com as firmas, assina compromissos com os empreendedores identitários, joga com os poderes mais banais (influência, negociatas, trocas desiguais). A haver soberania, esta torna-se um recurso de barganha, esquecendo a sua nobreza e sua excepcionalidade (BADIE, 1999, p.111).

É importante destacar, contudo, que somente um poder formalmente instituído pode utilizar porções do seu espaço (devidamente territorializadas) para barganhar a soberania. Esta pode ser barganhada em espaços específicos de um território estatal ou para todo o espaço. A realização da Copa do Mundo de futebol no Brasil (2014) é um exemplo no que se refere ao consumo de bebidas nos estádios. Proibido pela legislação brasileira, o consumo foi permitido durante o evento realizado no país. Espaços intensamente territorializados possuem maior valor estratégico no que tange à barganha de soberania, pois sabe-se que as permissões concedidas pela barganha gerarão de fato condições de exclusividade, à medida que se encontra diminuta a possibilidade de ocorrência de poderes paralelos concorrentes que atuam sem a permissão do Estado. É esta permissão, muitas vezes pontual, que gera algumas contradições: o Estado "ao mesmo tempo em que libera as fronteiras no sentido da livre circulação econômica, atua num movimento inverso no que diz respeito ao controle da circulação da força de trabalho e refugiados políticos" (HAESBAERT, 2012, p.211).

A porosidade, assim, é produzida pela legislação. No caso brasileiro, existem portas porosas nas fronteiras, que permitem, por meio da legislação das Áreas de Livre Comércio, a importação livre de impostos. Das nove ALCs brasileiras, cinco estão plenamente 
regulamentadas (Tabela 1) e possuem, dentre outros benefícios, a importação livre de impostos. Existe uma pressão que parte do interior dos municípios acerca da plena implementação dos termos das ALCs, o que faria com que todas estas áreas contempladas pela política territorial de exceção fossem beneficiadas com as importações livres de imposto. É importante considerar que em fronteiras porosas, sobretudo para as comunidades fronteiriças e devido à sua condição de interdependência, as questões internacionais tornam-se tão relevantes quanto às questões domésticas.

Microestados tendem a ser porosos. A sua pequena extensão territorial é incompatível com as necessidades de abastecimento de uma sociedade moderna contemporânea, fazendo com que as suas fronteiras sejam quase imperceptíveis no que se refere ao fluxo de mercadorias. Países com pequena diversificação econômica também tendem a ser mais porosos, por razões similares. A Bolívia, por exemplo, possui 15 zonas francas, sendo que as mesmas possuem regulamentação distinta. Existem zonas francas de incentivo comercial, industrial e ambos. Parcela destas zonas francas situa-se junto aos limites internacionais, como é o caso das cidades gêmeas de Cobija, junto ao Brasil e Desaguadero, junto ao Peru. O grande número de zonas francas na Bolívia evidencia a importância desta estratégia como elemento de gestão territorial do país.

Zona Franca é a área estabelecida dentro do território nacional onde se pode introduzir - temporariamente -, à espera de um destino posterior, mercadorias nacionais ou estrangeiras sem submetê-las ao pagamento de impostos aduaneiros. O objetivo do regime é a geração de empregos sustentáveis e capacitação permanente, a atração de investimentos intensivos principalmente em mão de obra, a captação e desenvolvimento de tecnologia, a geração de valor agregado e o desenvolvimento de uma infraestrutura comercial, industrial e de serviços vinculados ao comércio internacional para a realização de processos produtivos destinados ao mercado interno e fundamentalmente às exportações e a facilitação do comércio (BOLÍVIA, 2015).

O quadro a seguir lista as zonas francas bolivianas, destacando aquelas que se situam junto ao limite territorial do país.

Quadro 4- Zonas Francas Bolivianas

\begin{tabular}{|c|c|c|c|}
\hline Zona Franca & Departamento & Tipo & $\begin{array}{c}\text { Situa-se junto ao limite } \\
\text { internacional }\end{array}$ \\
\hline Desaguadero & La Paz & Comercial & Sim \\
\hline La Paz Comercial & La Paz & Comercial \\
\hline Zona Franca Industrial & La Paz & Industrial & Não \\
\hline
\end{tabular}




\begin{tabular}{|c|c|c|c|}
\hline GIT La Paz & & & \\
\hline $\begin{array}{c}\text { Zona Franca de } \\
\text { Patacamaya }\end{array}$ & $\mathrm{La} \mathrm{Paz}$ & Industrial & Não \\
\hline Cochabamba & Cochabamba & Comercial e Industrial & Não \\
\hline Puerto Aguirre & Santa Cruz & Comercial & Sim \\
\hline Puerto Suarez & Santa Cruz & Comercial e Industrial & Sim \\
\hline Santa Cruz Winner & Santa Cruz & Comercial e Industrial & Não \\
\hline Santa Cruz Warnes & Santa Cruz & Comercial e Industrial & Não \\
\hline $\begin{array}{c}\text { Zona Franca de San } \\
\text { Matías }\end{array}$ & Santa Cruz & Comercial & Sim \\
\hline Oruro & Oruro & Comercial e Industrial & Não \\
\hline Villazón & Potosi & Comercial & Não \\
\hline Yacuiba & Tarija & Comercial & Não \\
\hline Guayaramirim & Beni & Comercial & Sim \\
\hline Cobija & Pando & Comercial e Industrial & Sim \\
\hline
\end{tabular}

Fonte: BOLÍVIA, 2015, organizado pelo autor.

No caso boliviano, a política das zonas francas não é uma política de fronteiras; tratase de uma política nacional de um país dotado de baixa diversidade econômica. Nota-se, por meio dos dados apresentados pela tabela 2, que o gás natural foi responsável por 47,02 \% das receitas globais das exportações bolivianas em 2012 e 50,76\% em 2013. Esta concentração demonstra a baixa diversificação econômica do país.

Tabela 2 - Principais produtos exportados pela Bolívia ao mundo em volume negociado nos anos de 2012 e 2013

\begin{tabular}{ccccc}
\hline Produto & Toneladas & $\begin{array}{c}\text { Em milhares de } \\
\text { dólares FOB }\end{array}$ & Toneladas & $\begin{array}{c}\text { Em milhares de } \\
\text { dólares FOB }\end{array}$ \\
Gás Natural & 19.463 .427 & 5.478 .523 & 22.536 .058 & 6.113 .448 \\
Minerais de Prata & 15.744 & 986.006 & 17.514 & 836.456 \\
Zinco & 817.548 & 736.790 & 838.915 & 750.270 \\
Torta de Soja & 1.185 .027 & 496.795 & 1.426 .882 & 610.379 \\
Petróleo & 402.953 & 313.306 & 528.809 & 419.702 \\
Estanho & 13.966 & 289.433 & 14.957 & 333.790 \\
Ouro & 2 & 90.034 & 9 & 330.811 \\
\hline
\end{tabular}




\begin{tabular}{|c|c|c|c|c|}
\hline Grão de Soja & 273.346 & 142.716 & 554.978 & 251.680 \\
\hline Azeite de soja & 233.673 & 262.732 & 274.252 & 247.252 \\
\hline $\begin{array}{c}\text { Rejeito de metal } \\
\text { precioso }\end{array}$ & 27 & 982.019 & 154 & 206.869 \\
\hline Chumbo & 157.785 & 157.683 & 160.662 & 167.240 \\
\hline Quinoa & 25.899 & 78.912 & 35.063 & 153.259 \\
\hline Prata bruta & 201 & 189.160 & 203 & 148.012 \\
\hline Castanha do Brasil & 21.423 & 143.806 & 20.480 & 128.420 \\
\hline Joias & 4 & 58.861 & 7 & 114.329 \\
\hline Total & 23.742 .178 & 11.649 .930 & 27.780 .760 & 12.042 .660 \\
\hline
\end{tabular}

Fonte: INE, 2013. apud Instituto Boliviano de Comercio Exterior (IBCE), 2013.

A baixa diversificação econômica demonstrada pela especialização das exportações bolivianas se opõe a maior pulverização das importações, como atesta a tabela 3.

Tabela 3- Principais produtos importados pela Bolívia em dólares nos anos de 2012 e 2013

\begin{tabular}{ccc}
\hline Produto & 2012 & 2013 \\
Combustíveis & $\begin{array}{c}\text { Expresso em } \\
\text { milhares de US\$ }\end{array}$ & $\begin{array}{c}\text { Expresso em } \\
\text { milhares de US\$ } \\
\text { FOB }\end{array}$ \\
Permutadores de Calor & $\begin{array}{c}\text { FOB } \\
\text { Barras de ferro }\end{array}$ & 920.960 \\
Gasolina com tratamento especial & 815.866 & 298.345 \\
Veículos para o transporte de mercadorias & 44.884 & 211.073 \\
Tratores & 180.202 & 190.309 \\
Veículos de cilindradas entre 1500 e 3000 CM3 & 139.932 & 142.590 \\
Turbinas & 117.373 & 116.158 \\
Medicamentos & 79.102 & 98.633 \\
Máquinas & 76.598 & 81.154 \\
Total & 68.806 & 71.360 \\
\hline
\end{tabular}

Fonte: INE, 2013. apud Instituto Boliviano de Comercio Exterior (IBCE), 2013.

Em 2012, 10,37\% das importações bolivianas foram classificadas como “combustíveis", enquanto que em 2013 observou-se 9,92\%. Os combustíveis foram o 
principal item importado pela Bolívia. Este cenário bem diferente das exportações bolivianas, evidencia a especialização econômica do país e ajuda a explicar a política das zonas francas, que constrói a porosidade não só das suas fronteiras nacionais como também das suas entranhas.

\section{O colapso das fronteiras}

O colapso da fronteira é uma condição espaço-temporal da fronteira que não possui linearidade. Ao contrário do que se viu na condição de porosidade, que é necessário ter, anteriormente, a condição da força, o colapso pode ocorrer mesmo em fronteiras que jamais experimentaram forte processo de territorialização.

O colapso da fronteira acompanha aderrocada do próprio Estado, fazendo-o se enquadrar na categoria dos Estados Falidos, bastante abordada pelos estudos políticos. Como característica comum, tais Estados experimentam "a implosão das estruturas de autoridade e legitimidade que, de um só golpe, aniquilam a sua soberania" (BADIE,1999, p.124). Neste caso, não é só a fronteira que entra em colapso, mas o Estado como um todo. É razoável considerar que, por se encontrar geralmente menos servidas de malhas das redes que cobrem o território, as fronteiras são uma das porções mais sintomáticas do território estatal colapsado. Desde o fim da Guerra Fria os Estados Falidos passaram a chamar muita atenção da comunidade internacional. Estes Estados "cometem abusos dos direitos humanos, provocam grandes desastres humanitários, geram grandes ondas de emigração e atacam seus vizinhos. Desde 11 de setembro, também ficou claro que eles dão abrigo a terroristas internacionais" (FUKUYAMA, 2005, p.123-124).

O colapso da fronteira é um processo de desterritorialização do espaço. Não pode ser comparada à condição espaço-temporal da fraqueza da fronteirapois exibe diferenças significativas: por se tratar de um espaço de poder desconstruído, traz as marcas de fluxos interrompidos e/ou modificados, bem como a presença de agentes desterritorializante nele atuando. Enquanto que na condição da fraqueza, a ausência parece ser a palavra de ordem, em múltiplos sentidos.

Apesar da reconhecida atuação do poder paralelo em seu território, bem como a notória evasão de divisas e atuação do crime organizado transfronteiriço em vários ramos, o Brasil não é o melhor exemplo de fronteira em colapso. Estas, geralmente, estão vinculadas às guerras civis stricto sensu, que corroem a capacidade do Estado de fazer jus à sua soberania 
nos confins territoriais fronteiriços. Um processo paulatino de degradação econômica que acarrete na falência da atuação das instituições do Estado é outro sintoma. Para um cenário de colapso fronteiriço, os fluxos ilegais internacionais se avolumam em tal ordem ao ponto de tornar, comparativamente, os fluxos da legalidade (controlados pelo Estado), irrisórios.

\section{Quadro-síntese das condições espaço temporais da fronteira}

Uma vez apresentadas as quatro condições espaço temporais da fronteira, propusemos a sintetização das características de cada uma delas por meio de um quadro-síntese.

Quadro 5 - Quadro-síntese das condições espaço-temporais da fronteira

\begin{tabular}{|c|c|}
\hline Condição Espaço-Temporal da Fronteira & Características \\
\hline \multirow{3}{*}{ Fraqueza } & Dificuldades técnicas para se estabelecer os limites \\
\hline & Reconhecimento internacional não consensual \\
\hline & $\begin{array}{l}\text { Fragilidade de conexão das fronteiras com os } \\
\text { centros de comando e controle }\end{array}$ \\
\hline \multirow{6}{*}{ Força } & $\begin{array}{l}\text { Avanços superam as dificuldades técnicas para o } \\
\text { estabelecimento dos limites }\end{array}$ \\
\hline & Fundação das cidades vigilantes \\
\hline & Reconhecimento dos limites por parte dos vizinhos \\
\hline & $\begin{array}{l}\text { Adensamento das redes que conectam os centros } \\
\text { de comando e controle à fronteira }\end{array}$ \\
\hline & $\begin{array}{l}\text { Definição institucional da extensão da faixa de } \\
\text { fronteira }\end{array}$ \\
\hline & $\begin{array}{l}\text { Aplicação de políticas direcionadas ao } \\
\text { fortalecimento econômico orientado para o espaço } \\
\text { intranacional }\end{array}$ \\
\hline \multirow{4}{*}{ Porosidade } & $\begin{array}{l}\text { Aplicação de políticas direcionadas ao } \\
\text { fortalecimento econômico orientado para o espaço } \\
\text { internacional }\end{array}$ \\
\hline & $\begin{array}{l}\text { Fluxos transnacionais tornam-se relevantes frente } \\
\text { aos fluxos intranacionais }\end{array}$ \\
\hline & $\begin{array}{l}\text { Questões internacionais tornam-se tão relevantes } \\
\text { quanto às questões domésticas para a comunidade } \\
\text { fronteiriça }\end{array}$ \\
\hline & $\begin{array}{l}\text { Fluxos transnacionais da legalidade (controlados } \\
\text { pelo estado) irrisórios frente aos fluxos da } \\
\text { ilegalidade. }\end{array}$ \\
\hline
\end{tabular}




\begin{tabular}{|l|l|}
\hline Colapso & $\begin{array}{l}\text { Sintomas geralmente associados à condição de } \\
\text { Estado Falido se manifestam notoriamente, tais } \\
\text { como a deslegitimação do Estado, a falência dos } \\
\text { serviços públicos, o desrespeito aos direitos } \\
\text { humanos e o registro de fluxo de refugiados. }\end{array}$ \\
\hline
\end{tabular}

Fonte: Organizado pelo autor

\section{Considerações Finais}

As quatro condições espaço-temporais da fronteira não se constituem, como pode ser visto, como estágios temporais. Dessa forma, não é esperado que tais condições apresentemse como etapas necessárias de um processo evolutivo irremediável. Mais que isso, a tipologia apresentada neste artigo não trata-se de uma condição semanticamente isolada e impermeável, sendo que determinadas fronteiras podem reunir características de tipologias distintas. Outrossim, viu-se que, sobretudo em países de grande extensão territorial e que por isso possuem faixas de fronteira colossais, a faixa de fronteira pode possuir trechos muito diferentes entre si. Dessa forma, um mesmo país pode possuir trechos de sua fronteira que se associam melhor a uma tipologia do que àquela identificada como a mais fortemente associada ao conjunto da fronteira.

As tipologias fronteiriças, como se viu, são muito sensíveis às mudanças conjunturais de ordem estrutural e econômica, bem como às decisões políticas. Se por um lado a territorialização permite o fortalecimento da fronteira, a desterritorialização pode levá-la ao colapso. A porosidade das fronteiras definidas neste trabalho exigem, por sua vez, a condição de fortalecimento das fronteiras, pois se trata do resultado de um processo de barganha de soberania, parafraseando Bertrand Badie (1999). Concluiu-se que espaços bem territorializados são aqueles que possuem maior valor em um processo de barganha de soberania.

O artigo apresentou ainda que a história do desenvolvimento e formação do território brasileiro possui três das quatro condições espaço temporais da fronteira bem definidos: a fraqueza, o fortalecimento e a porosidade, ainda que esta última seja muito limitada a determinados trechos do território.

\section{Referências Bibliográficas}

ABINZANO, Roberto Carlos. Lasregiones de frontera: espacioscomplejos de la resistência global. In: OLIVEIRA, T.C.M de (org.). Territórios sem limites: estudos sobre fronteiras. Campo Grande: UFMS, 113-130 p.

ANDRADE, Manuel Correia de. Geopolítica do Brasil. São Paulo: Ática, 1993, 64 p. 
AMIN, Ash. Spatialites of globalization.Environment and Planning A, London,Vol. 34, pag. $385-399,2002$.

BADIE, Bertrand. Um mundo sem soberania: os Estados entre o artifício e a responsabilidade. Lisboa: Instituto Piaget, 1999, 326 p.

BADIE, Bertrand. O fim dos territórios: Ensaio sobre a desordem internacional e sobre a utilidade social do respeito. Lisboa: Instituto Piaget, 1995, 304 p.

BOLÍVIA, Constituição Federal. Art.261, linha I. La Paz: 2009.

BOLIVIA. EmbajadadelBolivia em Brasil. Directorio de zonas francas. Disponível em http://www.embolivia.org.br/nota.php?idn=43. Acesso em 18 de julho de 2015.

BRASIL, Constituição Federal. Cap.II, Art.20, alínea XI, parágrafo II.Brasília: 1988.

BRASIL. Ministério da Integração Nacional/Secretaria de Programas Regionais/ Programa de Desenvolvimento da Faixa de Fronteira. Proposta de Reestruturação do Programa de Desenvolvimento da Faixa de Fronteira. Brasília: Ministério da Integração Nacional, 2005, $416 \mathrm{p}$.

BRASIL. Ministério da Integração Nacional/Secretaria de Programas Regionais/ Programa de Desenvolvimento da Faixa de Fronteira. Faixa de Fronteira: Programa de Desenvolvimento da Faixa de Fronteira. Brasília: Ministério da Integração Nacional, 2009, $64 \mathrm{p}$.

CERVO, Amado Luiz; BUENO, Clodoaldo. História da política exterior do Brasil. Brasília: Editora da Universidade de Brasília, 2012, 4ªEd., 595 p.

FUKUYAMA, Francis. Construção de Estados. Rio de Janeiro: Rocco, 2005, 168p.

HAESBAERT, Rogério. O mito da desterritorialização: do "fim dos territórios" à Multiterritorialidade. Rio de Janeiro: Bertrand Brasil, $7^{a}$ Ed., 2012, 372 p.

HISSA, Cássio Eduardo Viana. A mobilidade das fronteiras. Belo Horizonte: Editora UFMG, 2002, 316 p.

MACHADO, Lia Osório. Limites e Fronteiras: da alta diplomacia aos circuitos da ilegalidade. Revista Território, Rio de Janeiro, ano V, nº8, p.7-23, jan./jul., 2000.

MACHADO, Lia Osório. Limites, Fronteiras e Redes. In: STROHAECKER, Tania Marques, et. ali. Fronteiras e espaço Global. Porto Alegre: Associação dos Geógrafos Brasileiros, 1998, 111p.

MACHADO, Lia Osório. et.al. O desenvolvimento da faixa de fronteira: uma proposta conceitual-metodológica. In: OLIVEIRA, T.C.M. de (Org.). Território sem limites: estudo sobre as fronteiras. Campo Grande: UFMS, 2005, 87-112.

MATTOS, Carlos de Meira. Geopolítica e Teoria de Fronteiras. Rio de Janeiro: Biblioteca do Exército, 1990, 116 p.

RAFFESTIN, Claude. Por uma geografia do poder. São Paulo: Khedyr, 2012.

SENHORAS, Elói Martins. Regionalização Internacional e a inserção brasileira de micro áreas de livre comércio. VI Jornadas de laAsociaciónLatinoamericana de Relaciones Internacionales, Santiago, Jul. 2013, p.1-15.

SILVA, Leonardo Luiz Silveira da. O papel das cidades gêmeas de Brasiléia, Epitaciolândia e Cobija na intermediação das relações entre o Brasil e a Bolívia. Tese de Doutorado. Belo Horizonte: PUC-MG, Programa de Pós Graduação em Geografia - Tratamento da Informação Espacial, 2016, 322 p.

SUFRAMA, Áreas de Livre Comércio, Manaus, disponível emhttp://www.suframa.gov.br/invest/zona-franca-de-manaus-alc.cfm Acesso em 17 de julho de 2015.

Recebido em 13 de dezembro de 2017.

Aceito em 22 de março de 2018. 